\title{
OS NEGÓCIOS PROCESSUAIS NA TUTELA COLETIVA - BREVES APROXIMAÇÕES ${ }^{1}$
}

\section{PROCEDURAL AGREEMENTS AT COLLECTIVE LITIGATION-}

\section{SOME BRIFE NOTES}

Gustavo Osna

Professor Adjunto dos Programas de Graduação e de Pós-Graduação stricto sensu em Direito da PUC/RS. Doutor em Direito das Relações Sociais pela UFPR. Mestre em Direito das Relações Sociais pela UFPR. Bacharel em Direito pela UFPR. Membro do Instituto Brasileiro de Direito Processual. Advogado. Curitiba/PR. E-mail: gustavo@mosadvocacia.com.br

Isabelle Almeida Vieira

Mestranda em Direito, na área de concentração Teoria Geral da Jurisdição e Processo, pela PUC/RS. Bolsista integral CNPq. Especialista em Processo Civil pela UFRGS. Graduada em Direito pela PUC/RS. Advogada. Porto Alegre/RS. E-mail: isabelle.vieira93@edu.pucrs.br

RESUMO: O presente artigo possui como objeto a temática da celebração de acordos processuais na seara da tutela coletiva, tendo em vista as especificidades que marcam esse campo. Em síntese, demonstra-se que o problema central que se coloca, aqui, dialoga com as próprias peculiaridades que caracterizam a inserção do tema da autocomposição no processo coletivo. Além disso, indica-se que a própria porosidade que ainda marca a matéria dos negócios processuais exerce um papel nesse jogo. De todo modo, partindo do pressuposto de que a composição no processo coletivo é admissível, defende-se que o

\footnotetext{
${ }^{1}$ Artigo recebido em 20/04/2021 e aprovado em 13/07/2021.
} 
mesmo valeria para os negócios processuais. Ainda assim, essa admissibilidade não afasta a obrigatoriedade de que sejam adotadas cautelas para preservar a legitimidade dessas convenções.

PALAVRAS-CHAVE: Tutela Coletiva; Negócios Processuais; Autocomposição; Legitimidade.

ABSTRACT: This essay analyses the enforcement of procedural agreements at collective litigation, due to the peculiarities of such field. In sum, we argue that the main dilemmas here are coincident with those already present on collective settlements. Additionally, we defend that the very unclearness of procedural agreement boundaries plays a role in this game. Even though, considering that collective settlements are feasible and acceptable, we argue that the same admissibility should be applied to procedural agreements. Lastly, however, we remind that such admissibility does not exclude the need to pursue the legitimacy of those agreements.

KEYWORDS: Collective Litigation; Procedural Agreements; Settlement; Legitimacy.

SUMÁRIO: 1. Introdução. 2. A "Tutela Coletiva”: Um Conceito, Muitas Portas. 3. A Convencionalidade no Processo Coletivo e os Negócios Processuais. 4. Negócios Processuais na Tutela Coletiva: Da Admissão à Legitimidade. 5. Considerações Finais.

\section{Introdução}

Como é sabido, a tutela coletiva possui uma gama de especificidades e de peculiaridades, não podendo ser lida com os mesmos olhares dedicados ao processo individual. Nesse cenário, a compreensão dos seus institutos exige constantes ajustes e releituras capazes de aprimorar sua efetividade.

É nesse cenário que tem assumido especial importância o debate relacionado à admissibilidade de celebração de acordos ou de convenções nessa seara - levando em conta a impossibilidade de plena participação, na negociação, de todos os atores envolvidos. Essa 
discussão passa a ter destacada relevância principalmente após o ganho de pertinência da temática da autocomposição no processo civil de um modo geral, considerando a adoção de uma "política pública de estímulo às soluções extraídas do consenso". 2

Sob o mesmo prisma, também tem assumido fôlego a leitura ligada à possibilidade, no processo coletivo, de celebração de negócios jurídicos processuais. E é exatamente a esse objeto que o atual estudo se dedica. Afinal, referidas convenções, no processo coletivo, seriam admissíveis? Como elas dialogariam com as próprias idiossincrasias desse campo?

As indagações se revelam pertinentes, especialmente, quando levamos em consideração a legitimidade do instituto, tendo em vista o cariz essencialmente representativo existente nessa área. Ainda, para a referida análise, também se mostra importante o debate relacionado aos possíveis limites que se impõem em relação à celebração de negócios processuais - sejam os mesmos atinentes ao processo individual, sejam os justificáveis pela cautela que o próprio processo coletivo impõe.

É nesse sentido que, inserindo-se nesse campo, o atual ensaio investiga inicialmente, ainda que de modo breve, o conceito de "tutela coletiva" aqui adotado. Após, demonstra-se como esse panorama se articula com a autocomposição. Por último, afere-se de que maneira esse caminho pode levar ao discurso dos negócios jurídicos processuais, avaliando-se sua compatibilidade com a seara coletiva.

\section{A "Tutela Coletiva": Um Conceito, Muitas Portas}

Para nos aproximarmos do atual objeto de estudo, parece necessário, de maneira breve, tecer algumas considerações relacionadas à visão aqui adotada a respeito da "tutela coletiva" ${ }^{3}$. Ainda que sumariamente, o enfrentamento se torna necessário tendo em vista a centralidade do tema para o presente estudo. Afinal, que realidades estão inseridas nesse conceito? Qual sua extensão e seu propósito?

Procurando firmar essa premissa em poucas palavras, é aqui possível estabelecer que, em nossa visão, o conceito em questão faz menção a uma realidade bifronte. Nesse arranjo,

\footnotetext{
${ }^{2}$ PINHO, Humberto Dalla Bernardina de; VIDAL, Ludmila Camacho Duarte. Primeiras reflexões sobre os impactos do novo CPC e da Lei de Mediação no compromisso de ajustamento de conduta. Revista de Processo, v. 256, p. 371-409, jun. 2016, p. 378.

${ }^{3}$ Para um aprofundamento na temática, ver, ARENHART, Sérgio Cruz. OSNA, Gustavo. Curso de Processo Civil Coletivo. 3 ed. rev., atual. e ampl. Sâo Paulo: Ed. RT, 2021.
} 
de um lado, coloca-se a proteção de direitos essencialmente coletivos - revelando a impossibilidade de que a atuação jurídica seja percebida de forma limitada à sua feição individual e a inocuidade de se pensar a estrutura processual contrapondo apenas o sujeito (o particular) e o Estado. Inserem-se, aqui, interesses cuja titularidade não pode ser individualmente expressa ou reduzida ${ }^{4}$. Tais direitos pertenceriam a determinados grupos ou à própria coletividade, e a sua salvaguarda não constituiria mecanismo de proteção de um único sujeito, mas de satisfação de anseios metaindividuais.

É emblemática nesta guinada ideológica a ascensão da importância destinada ao "direito ao meio-ambiente equilibrado". Sua titularidade, por óbvio, não pertence a indivíduos determinados, não sendo factível que sua proteção seja objeto de divisão ou de livre disposição. Porém, o novo traçado dos direitos fundamentais materiais observou que o fato de o direito isoladamente a ninguém pertencer não acarreta na consequência de não ser essencial. Sua importância teria lugar perante toda a comunidade, de modo que sua proteção, longe de capricho, representaria medida inarredável.

Em termos normativos, a primeira manifestação dessa realidade, em nosso ordenamento, ocorreu por meio da figura da ação popular ${ }^{5}$, introduzida no direito pátrio pela Constituição Federal de 1934 e especialmente regulamentada pela Lei $n^{\circ}$ 4.717/1965 ${ }^{6}$. Em descrição bastante breve, a medida processual em análise representou artifício voltado a possibilitar que o cidadão ingressasse nominalmente em juízo com fito a questionar atos da Administração Pública que entendesse danosos ao patrimônio de entidades públicas. Esse objeto foi dilatado pela Constituição Federal de 1988, cujo art. $5^{\circ}$, inc. LXXIII, mantendo a figura da "ação popular", passou a prescrever seu cabimento para a defesa de mais vasta gama de atos lesivos ao patrimônio público, incluindo em seu âmbito de proteção os

\footnotetext{
4 "Dotados de altíssimo teor de humanismo e universalidade, os direitos da terceira geração tendem a cristalizar-se no fim do século XX enquanto direitos que não se destinam especificamente à proteção dos interesses de um indivíduo, de um grupo ou de determinado Estado. Têm primeiro por destinatário o gênero humano mesmo, num momento expressivo de sua afirmação como valor supremo em termos de existencialidade concreta". BONAVIDES, Paulo. Curso de Direito Constitucional. 25 ed. São Paulo: Malheiros, 2010. p.569

${ }^{5}$ CUNHA, Alcides Munhoz da. Evolução das Ações Coletivas no Brasil. In. Revista de Processo. n.77. São Paulo: Editora Revista dos Tribunais, 1995. p.225-228.

${ }^{6}$ Como destacam Rogério Lauria Tucci e José Rogério Cruz e Tucci, a ação popular foi introduzida no ordenamento brasileiro pela Constituição de 1934, mas - pela sua desarmonia com o regime posteriormente instituído - revogada pela Carta Política de 1937. Contudo, o instrumento voltou a ser positivado pela Constituição Federal de 1946 e, desde então, tem lugar em nosso cenário constitucional. TUCCI, Rogério Lauria. CRUZ E TUCCI, José Rogério. Constituição de 1988 e Processo. São Paulo: Saraiva, 1989.p.182.
} 
Revista Eletrônica de Direito Processual - REDP.

Rio de Janeiro. Ano 15. Volume 22. Número 3. Setembro a Dezembro de 2021

Periódico Quadrimestral da Pós-Graduação Stricto Sensu em Direito Processual da UERJ

Patrono: José Carlos Barbosa Moreira (in mem.). ISSN 1982-7636. pp. 410-433

www.redp.uerj.br

patrimônios histórico e cultural, além do meio-ambiente. Em resumo, assim, o cidadão que ingressa com a medida não age em favor de um interesse próprio, mas em defesa solidária do bem comum, contrapondo-se à Administração em favor da coletividade ${ }^{7}$.

Ao lado desse aspecto, e com campo de incidência ainda mais amplo, a tutela de direitos metaindividuais também é hoje chancelada em nosso processo pela previsão de cabimento da ação civil pública para defesa de direitos difusos e coletivos em sentido estrito. A segmentação entre ambas as categorias parece desnecessária e artificial, como já notado por Antonio Gidi ${ }^{8}$. De todo modo, o que nos importa aqui notar é que, inequivocamente, está-se nesse polo diante de interesses materialmente coletivos.

$\mathrm{Na}$ outra ponta de nossa processualística coletiva, contudo, parece haver figura diversa. Ali, o que entra em cena é a proteção aglutinada de interesses individuais. Para ilustrar o cenário, deve-se reconhecer que, em perspectiva comparada, diferentes países construíram ferramentas procedimentais diversas voltadas a lidar de maneira mais racional com demandas similares ${ }^{9}$. Diante disso, foram forjadas diferentes maneiras para a sua

\footnotetext{
${ }^{7}$ Nas palavras de Hely Lopes Meirelles, a ação popular representaria um "instrumento de defesa dos interesses da coletividade", cuja titularidade seria indistintamente conferida a todos os cidadãos. Em igual sentido, é válida a menção a José Afonso da Silva, responsável por conceituar o instrumento como "instituto processual civil, outorgado a qualquer cidadão como garantia político-constitucional (ou remédio constitucional), para a defesa do interesse da coletividade". Cita-se, MEIRELLES, Hely Lopes. Mandado de segurança e ação popular. 10 ed. São Paulo: Revista dos Tribunais, 1985. p.82. SILVA, José Afonso da. Curso de Direito Constitucional Positivo. 32 ed. São Paulo: Malheiros, 2009. p.464. Ainda, a respeito da temática, ver ARENHART, Sérgio Cruz. OSNA, Gustavo. Ob. cit. p.379 e ss.

${ }^{8} \mathrm{O}$ autor ressalta que a conceituação, em seu momento primitivo, exerceu caráter pedagógico junto ao jurista brasileiro, mas salienta que "hoje, ao lermos essas conceituações italianas "antigas", temos a exata dimensão de que elas refletiam um estado de conhecimento bastante rudimentar sobre o fenômeno da tutela jurisdicional dos direitos de grupo. É desalentador constatar que livros brasileiros publicados neste século ainda repetem acriticamente definições de direitos difusos e coletivos lançadas pelos autores italianos trinta anos atrás, sem a menor aplicação prática ou teórica para o direito positivo brasileiro". Com isso, alerta que "corremos o risco de criar uma "jurisprudência de rótulos", em que os fatos precisam ser subsumidos à letra da lei, em vez de um sistema prático e funcional". GIDI, Antonio. Rumo a um Código de Processo Civil Coletivo. Rio de Janeiro: Forense, 2008. p.202-210. Também assim, ARENHART, Sérgio Cruz. OSNA, Gustavo. Ob. cit. p.66.

${ }^{9}$ Ver aqui, por todos, MENDES, Aluisio Gonçalves de Castro. Ações Coletivas no Direito Comparado e Nacional. 2 ed. São Paulo: Ed. RT, 2009. Também, GIDI, Antonio. Class Actions in Brazil: A Model for Civil Law Countries. In. The American Journal of Comparative Law. n.51. Michigan: University of Michigan Law School, 2003. Ainda, ARENHART, Sérgio Cruz. A tutela coletiva de interesses individuais: para além da proteção dos interesses individuais homogêneos. São Paulo: Ed. RT, 2013. GRINOVER, Ada Pellegrini. Os processos coletivos nos países de civil Law e common Law: uma análise de direito comparado. São Paulo: Ed. RT, 2008. HODGES, Christopher. The Reform of Class and Representative Actions in European Legal Systems. Oxford: Hart Publishing, 2008. MULHERON, Rachael. The Class Action in Common Law Legal Systems: A Comparative Perspective. Oxford: Hart Publishing, 2004.
} 
Rio de Janeiro. Ano 15. Volume 22. Número 3. Setembro a Dezembro de 2021

Periódico Quadrimestral da Pós-Graduação Stricto Sensu em Direito Processual da UERJ

Patrono: José Carlos Barbosa Moreira (in mem.). ISSN 1982-7636. pp. 410-433 www.redp.uerj.br

coletivização; variados meios de aglutinação, devidamente inseridos no âmbito do processo coletivo ${ }^{10}$.

Esse ponto pode ser mais claramente compreendido pelo recurso à via exemplificativa. Com esse propósito, suponhamos que uma companhia telefônica, com relevante poder de mercado junto ao público brasileiro, realiza uma mesma cobrança de todos os seus consumidores. Imaginemos que esse débito possui legalidade questionável, suscitando diferentes indagações.

Nessa hipótese, é certo que qualquer usuário vitimado pela cobrança poderia ingressar em juízo pleiteando a sua reparação. Como consequência, seria viável que o Judiciário recebesse um verdadeiro tsunami de ações relacionadas a essa questão: diferentes consumidores, com domicílios e capacidades materiais também diversas, poderiam litigar individualmente sobre o mesmo problema.

Contudo, mesmo uma análise preliminar revela que esse cenário traria uma série de inconvenientes. Em síntese, surgiriam óbices tanto à gestão jurisdicional quanto ao acesso à justiça, na medida em que: (i) a pulverização do debate permitiria que diferentes sujeitos, embora questionando a mesma cobrança, recebessem respostas diametralmente opostas; (ii) a análise reiterada do mesmo problema comprometeria a própria administração do serviço justiça, impondo uma utilização pouco razoável dos seus recursos; e (iii) do mesmo modo, a pulverização ocasionaria uma instabilidade contínua e indesejada.

Foi para lidar com esse tipo de problema que, como dito, várias localidades procuraram otimizar o tratamento processual de questões análogas. A ideia central aqui trazida pode ser assim resumida: existindo inúmeros conflitos similares passíveis de apreciação atômica, seria mais apropriado agrupá-los em algum sentido para permitir seu enfrentamento coletivo. E, na definição do melhor caminho para esse fim, diferentes percursos podem ser traçados. De modo notório, entra em cena, por exemplo, o regime norteamericano da class action (ou, como suscitado por Issacharoff ${ }^{11}$, os regimes das class

\footnotetext{
10 Ver, OSNA, Gustavo. Coletivização total e coletivização parcial: aportes comparados e o processo civil brasileiro. In. Revista de Processo Comparado. v. 1. São Paulo: Ed. RT, 2015. p. 115-138. Também, OSNA, Gustavo. Direitos Individuais Homogêneos: Pressupostos, Fundamentos e Aplicação no Processo Civil. São Paulo: Ed. RT, 2014. Ainda, especialmente, ARENHART, Sérgio Cruz. OSNA, Gustavo. Ob. cit.

11 "As the name would imply, the Rule 23 (a) prerequisites for class certification are just that: prerequisites. Rule $23(b)$ then requires that a court finding that the prerequisites are met determine which of the three primary sorts of class action is to be created. The distinct class action types correspond to familiar problems in the joinder rules, responding to competing demands for insufficient resources, the indivisibility of the
} 
Rio de Janeiro. Ano 15. Volume 22. Número 3. Setembro a Dezembro de 2021

Periódico Quadrimestral da Pós-Graduação Stricto Sensu em Direito Processual da UERJ

Patrono: José Carlos Barbosa Moreira (in mem.). ISSN 1982-7636. pp. 410-433 www.redp.uerj.br

actions) ${ }^{12}$. Ainda, ganham relevo técnicas de coletivização parcial, como o modelo alemão de Musterverfahren e o sistema inglês de Group Litigation Order ${ }^{13}$. Enfim, há uma pluralidade de portas, voltadas a contribuir, em alguma medida, com a efetividade do processo e do sistema de justiça ${ }^{14}$.

\section{A Convencionalidade no Processo Coletivo e os Negócios Processuais}

A partir da compreensão dos pilares elementares da tutela coletiva, conclui-se prontamente que se trata de matéria provida de claras especificidades. Em outros termos, não há como compreender o processo coletivo sem levar em conta sua particularidade. Trata-se de legado da própria dinâmica representativa que norteia esse campo - fazendo com que as garantias do processo e a própria composição subjetiva da disputa devam ser, aqui, objeto de releituras e de desconstruções ${ }^{15}$.

Realmente, seja encarando a disciplina sob o ângulo da proteção dos direitos metaindividuais, seja a observando sob o prisma da proteção aglutinada de direitos individuais, a conclusão a ser alcançada em relação a esse aspecto será a mesma. Nos dois casos, é presumível (e mesmo necessário) que nem todos os sujeitos impactados pela disputa possam tomar parte em sua composição. Como consequência, é imprescindível buscar um outro critério de legitimidade - o que leva à necessidade de construções ligadas a temas como o controle de representatividade adequada e a valorização de figuras como os amici curiae $^{16}$.

De qualquer modo, para as atuais finalidades, o que se deve notar é que a partir dessa peculiaridade surge um debate provido de especial importância na seara da tutela coletiva.

\footnotetext{
remedies sought by the class, or the simple efficiency commands of aggregate treatment of small claims that would not merit prosecution on their own". ISSACHAROFF, Samuel. Civil Procedure. New York: Foundation Press, 2005. p.79.

${ }^{12}$ Sobre o tema, na nossa doutrina, ver GIDI, Antonio. A Class Action como instrumento de tutela coletiva de direitos. São Paulo: Ed. RT, 2007. ROQUE, André Vasconcelos. Class Action - Ações Coletivas nos Estados Unidos: o que podemos aprender com eles?. Salvador: Editora JusPodivm, 2013. CRUZ E TUCCI, José Rogério. Class action e mandado de segurança coletivo, diversificações conceptuais. São Paulo: Ed. RT, 1990. ${ }^{13}$ Nesse particular, ver CABRAL, Antonio do Passo. O novo procedimento-modelo (Musterverfahren) alemão: uma alternativa às ações coletivas. In. Revista de Processo. v.147. São Paulo: Ed.RT, 2007. ANDREWS, Neil. O Moderno Processo Civil. Trad. Teresa Arruda Alvim Wambier. São Paulo: Ed. RT, 2009. OSNA, Gustavo. Coletivização total e coletivização parcial. ARENHART, Sérgio Cruz. Ob. cit.

${ }^{14}$ Constatando essa abertura, ver, passim, ARENHART, Sérgio Cruz. OSNA, Gustavo. Ob. cit.

${ }^{15}$ Ver aqui, passim, ARENHART, Sérgio Cruz. OSNA, Gustavo. Ob. cit.

${ }^{16}$ Assim, passim, ARENHART, Sérgio Cruz. OSNA, Gustavo. Ob. cit.
} 
Afinal, seria aqui possível admitir a celebração de acordos ou de convenções? Considerando a impossibilidade de plena participação dos atores envolvidos, a negociação seria uma trilha viável? Em caso positivo, como legitimar sua concretização e garantir sua efetividade?

Levando em conta o próprio ganho de importância da temática da autocomposição no processo civil de um modo geral, seria esperado que também na processualística coletiva esse movimento fosse experimentado. Em outras palavras, ainda que as críticas formuladas ao fomento de acordos sejam conhecidas ${ }^{17}$, o tema é realidade crescente em nosso ambiente processual - o que fez com que também no campo da tutela coletiva assumisse um importante papel.

Com efeito, colocando luzes sobre essa seara, é possível notar imediatamente que, nela, “essa valorização da autocomposição parece se mostrar relevante, ainda, em um especial momento da atividade processual. É que, ainda que nem sempre seja aí viável ou oportuno alcançar alguma espécie de autocomposição atinente ao conteúdo da resolução da disputa (isso é, à eventual procedência ou improcedência do pleito inicial), o caminho pode ser o mais adequado para a própria efetivação da proteção judicialmente reconhecida. Nessas hipóteses, questões como a necessidade de cooperação da parte ré ou a complexidade intrínseca à realidade litigiosa podem fazer com que a efetivação consensual da decisão se mostre o melhor caminho possível" ${ }^{18}$.

Do mesmo modo, o avanço da questão assumiria especial pertinência "ao se observar processos coletivos relacionados a problemas complexos. É que, nessas situações, é usual que a jurisdição se depare com situações nas quais não há, propriamente, antagonismo entre os interessados, no sentido de um conflito de interesses entre eles que, para ser resolvido, exige que alguém ganhe à custa do seu adversário. Ao contrário, é muito frequente que tais casos envolvam problemas em que há consenso de todos de que a situação atual não é boa e não está conforme o Direito; há, no entanto, dissenso quanto aos caminhos que devem ser trilhados para obter o aperfeiçoamento da situação ou há limites concretos que dificultam ou impedem que essa melhora se dê de forma espontânea" ${ }^{19}$.

\footnotetext{
${ }^{17}$ Ver, de modo notório, FISS, Owen. Against Settlement. In. Yale Law Journal. n.93. New Haven: Yale University Press, 1983.

${ }^{18}$ ARENHART, Sérgio Cruz. OSNA, Gustavo. Ob. cit.

${ }^{19}$ ARENHART, Sérgio Cruz. OSNA, Gustavo. Ob. cit.
} 
A partir disso, assim, torna-se clara a proeminência de que a autocomposição pode se revestir no campo do processo coletivo. Mais que isso, acredita-se, ainda, que eventual argumento ligado à disponibilidade do direito não fulmina essa conexão. Pelo contrário, também aqui é possível identificar a existência de feixes de interesse suscetíveis de negociação e de convenção ${ }^{20}$.

Desse modo, considera-se plenamente admissível a composição na seara do processo coletivo. E esse aspecto leva à outra indagação que integra o cerne do presente ensaio: admitida a possibilidade de convenção a respeito do direito material subjacente à tutela coletiva, seria possível pensar, também, na contratualização de elementos afetos ao próprio procedimento construído para essa seara? Mais bem dizendo, seria aceitável, do mesmo modo, a celebração na esfera coletiva de negócios jurídicos processuais?

Recuando um passo para compreender a questão, perceba-se que aqui, por "negócios jurídicos processuais", faz-se menção, essencialmente, à possibilidade conferida às partes de pactuarem a respeito de regras, de parâmetros ou de posições inerentes ao processo e a seu procedimento ${ }^{21}$. Trata-se, enfim, de permitir que os próprios litigantes, por meio de um ato de vontade, alterem o desenho tradicional a que a resolução de conflitos deveria se sujeitar - agregando a ele outras cores e modificando seus traçados originais. Oferece-se, com isso, maior disponibilidade às partes e maior prestígio à ideia de autonomia da vontade 22 .

Para enquadrar esse tema, é relevante salientar que a matéria da contratualização do processo adquiriu especial relevância na doutrina e na realidade brasileira ao longo dos

\footnotetext{
${ }^{20}$ Sobre o tema, emoldurando a diferença assumida por essa disponibilidade nos dois ambientes inseridos no contexto da tutela coletiva (isso é, na proteção de direitos metaindividuais e na coletivização de interesses individuais), ver, ARENHART, Sérgio Cruz. OSNA, Gustavo. Ob. cit. p.268-276.

${ }^{21} \mathrm{Na}$ diç̧ão de Fredie Didier Jr., "negócio processual é o fato jurídico voluntário, em cujo suporte fático se confere ao sujeito o poder de regular, dentro dos limites fixados no próprio ordenamento jurídico, certas situações jurídicas processuais ou alterar o procedimento. Sob esse ponto de vista, o negócio jurídico é fonte de norma jurídica processual e, assim, vincula o órgão julgador, que, em um Estado de Direito, deve observar e fazer cumprir as normas jurídicas válidas, inclusive as convencionais". DIDIER JR., Fredie. Negócios jurídicos processuais atípicos no Código de Processo Civil de 2015. In. Revista Brasileira da Advocacia. v.1. São Paulo: Ed. RT, 2016. Por sua vez, Antonio do Passo Cabral salienta que "convenção (ou acordo) processual é o negócio jurídico plurilateral, pelo qual as partes, antes ou durante o processo e sem necessidade de intermediação de nenhum outro sujeito, determinam a criação, modificação e extinção de situações jurídicas processuais, ou alteram o procedimento". CABRAL, Antonio do Passo. Convenções Processuais. Salvador: JusPodivm, 2016. p.68.

${ }^{22}$ Assim, OSNA, Gustavo. "Contratualizando o processo": três notas sobre os negócios jurídicos processuais (e seu possível "fracasso"). Revista Eletrônica de Direito Processual da UERJ, Rio de Janeiro, ano 14, v. 21, n. 2, p. 163-185, mai./ago. 2020,
} 
Rio de Janeiro. Ano 15. Volume 22. Número 3. Setembro a Dezembro de 2021

Periódico Quadrimestral da Pós-Graduação Stricto Sensu em Direito Processual da UERJ

Patrono: José Carlos Barbosa Moreira (in mem.). ISSN 1982-7636. pp. 410-433 www.redp.uerj.br

últimos anos. Isso se deu, notadamente, pelo fato de o Código de Processo Civil de 2015 ter chancelado de maneira expressa, em seu art. 190, a possibilidade de celebração de negócios jurídicos processuais atípicos ${ }^{23}$. Considera-se que a previsão se deu por especial influência do Direito Francês, o qual inaugurou essa tendência a partir da década de 1980 com o contrat de procédure. ${ }^{24}$ Segundo Loïc Cadiet, na França, os acordos processuais ganharam força por meio da contratualização contemporânea das relações sociais, a qual se ligava à decadência do centralismo estatal e de seu corolário na categoria de produção normativa: o legicentrismo. ${ }^{25}$

Em nossa realidade atual, é viável observar essa mesma lógica, resultando na passagem de uma ordem jurídica imposta exclusivamente pelo legislador para uma ordem jurídica negociada pelas partes ${ }^{26}$. Em última análise, o tema dialoga com a própria decadência do mito da completude do texto legislativo ${ }^{27}$, o qual refletia também no processo. Por decorrência, passa a ser notado que qualquer procedimento previamente fixado é incapaz de dar conta da riqueza da realidade - exigindo janelas de abertura.

Com efeito, por bastante tempo, pouca margem de espaço foi conferida no processo civil brasileiro às partes no sentido de permitir a adaptação do procedimento. Essa situação se sustentava na medida em que o direito processual era considerado ramo pertencente ao Direito Público (o qual regula a atividade estatal consistente no exercício da jurisdição), ${ }^{28} \mathrm{o}$ que reduzia o flanco ofertado à autonomia privada. Nesse cenário, o tema dos negócios jurídicos processuais foi muito pouco examinado durante o século XX.

Barbosa Moreira, nesse ponto, lecionava que "não se poderia reconhecer a autonomia da vontade, no campo processual, atuação tão ampla como a que se lhe abre no terreno

\footnotetext{
${ }^{23}$ Artigo 190, caput, do CPC: "Versando o processo sobre direitos que admitam autocomposição, é lícito às partes plenamente capazes estipular mudanças no procedimento para ajustá-lo às especificidades da causa e convencionar sobre os seus ônus, poderes, faculdades e deveres processuais, antes ou durante o processo".

${ }^{24}$ MARINONI, Luiz Guilherme; ARENHART, Sérgio Cruz; MITIDIERO, Daniel. Novo curso de processo civil: teoria do processo civil. v. 1. 3. ed. São Paulo: Revista dos Tribunais, 2017, p. 408.

${ }^{25}$ CADIET, Loïc. Los acuerdos procesales en derecho francés: situación actual de la contractualización del proceso y de la justicia en Francia. Civil Procedure Review, v. 3, n. 3, p. 3-35, ago./dez. 2012. Disponível em: $<$ http://www.civilprocedurereview.com/teoria-geral-do-processo/456-los-acuerdos-procesales-en-derechofrances-situacion-actual-de-la-contractualizacion-del-proceso-y-de-la-justicia-en-francia> Acesso em: 15 jun. 2020, p. 4-5.

${ }^{26}$ CABRAL, Antonio do Passo. Convenções processuais. 2. ed. Salvador: JusPodivm, 2018, p. 187.

${ }^{27}$ Ver, sobre o tema, GROSSI, Paolo. Primeiras Lições sobre o Direito. Trad. Ricardo Marcelo Fonseca. Rio de Janeiro: Forense, 2005. p.30.

${ }^{28}$ SILVA, Ovídio Araújo Baptista da; GOMES, Fábio Luiz; SILVA, Jaqueline Mielke; BAPTISTA, Luiz Fernando. Teoria geral do processo civil. 6. ed. São Paulo: Revista dos Tribunais, 2011, p. 39.
} 
privatístico; no processo, ramo do direito público, deveria considerar-se proibido tudo quanto não fosse permitido". ${ }^{29}$ Dessa forma, e inexistindo uma cláusula geral explícita que chancelasse a negociação processual atípica, o entendimento era o de que as partes não poderiam dispor acerca do procedimento previamente disciplinado pelo legislador processual civil.

Apreciando a questão, Antonio do Passo Cabral sustenta que "tradicionalmente, em decorrência da concepção publicista do processo, muitos autores compreendiam que a validade e eficácia dos acordos processuais dependiam de interposição legislativa. Somente a lei poderia estabelecer norma processual, e portanto as convenções processuais só seriam admissíveis quando a lei fosse expressamente previdente: só existiriam acordos processuais típicos, tais como o compromisso arbitral, o foro de eleição, as convenções sobre os prazos, etc" 30 .

Embora o procedimento não pudesse ser amplamente ditado pelos litigantes, vale, porém, consignar que já no Código de 1973 existiam poucas exceções a essa regra. Era possível que as partes convencionassem, por exemplo, acerca da suspensão do processo (art. 265, II); sobre a distribuição do ônus da prova (art. 333, § único); quanto à eleição de foro (art. 111); bem como sobre o adiamento da audiência (art. 453, I).

Diante desse contexto, era o legislador quem disciplinava o procedimento de forma praticamente exclusiva, com quase nenhuma participação dos atores processuais na sua construção - ou seja, a lei era a única fonte da norma processual. Indo além, aceitava-se essa situação, inclusive, pelo fato de uma das razões para se entender o processo civil como uma ciência autônoma ser justamente possuir um procedimento previamente previsto pelo legislador. ${ }^{31}$

Contudo, como mencionado, verifica-se atualmente uma tendência na mudança de titularidade acerca de quem dita o procedimento - passando de um cenário de exclusividade do legislador, mediante o procedimento comum e os procedimentos especiais, a um campo

\footnotetext{
${ }^{29}$ MOREIRA, José Carlos Barbosa. Convenções das partes sobre matéria processual. Revista de Processo, v. 33, p. 182-191, jan./mar. 1984, p. 184.

${ }^{30}$ CABRAL, Antonio do Passo. Convenções processuais. 2. ed. Salvador: JusPodivm, 2018, p. 98.

${ }^{31}$ MARINONI, Luiz Guilherme; ARENHART, Sérgio Cruz; MITIDIERO, Daniel. Novo curso de processo civil: tutela dos direitos mediante procedimento comum. v. 2. 2. ed. São Paulo: Revista dos Tribunais, 2016, p. 116.
} 
de maior liberdade para o juiz e as partes, mediante uma adaptação judicial ou privada possibilitando que o procedimento fique aberto a negociações. ${ }^{32}$

Não se desconhece que a rigidez de um procedimento previamente disciplinado pelo legislador tem por finalidade garantir maior segurança e previsibilidade ao resultado das atividades processuais. ${ }^{33}$ Todavia, considerando que o Estado "não é capaz de prever e criar abstratamente procedimentos adequados para todas as situações da vida", ${ }^{34}$ parece de fato imperioso que mecanismos e instrumentos que possibilitem a contratualização do processo sejam conferidos aos atores processuais, dando-se maior destaque à autonomia privada no processo.

Nesse sentido, Trícia Navarro Xavier Cabral dispõe que "no Brasil, que também segue o modelo da civil law, a forma preestabelecida do ato e do procedimento ainda é sinônimo de ordem, segurança e previsibilidade, capaz de evitar arbítrios e preferências dos agentes públicos frente aos particulares e assegurar a isonomia de tratamento entre os envolvidos na relação jurídica processual. Isso faz com que haja dificuldade em desapegar do modelo tradicional de processo, que confere pouca margem de disposição aos sujeitos processuais sobre a forma e sequência dos atos e do procedimento" 35 .

É partindo desse enfoque que o Código de 2015 passa a inaugurar uma previsão explícita que viabiliza a negociação atípica de posições do processo. Com isso, procura "tornar o processo jurisdicional um espaço mais propício para o exercício da liberdade" 36. Permite-se, assim, uma construção balizada pelo caso concreto, possibilitando às partes adaptarem o procedimento às peculiaridades e singularidades da relação de direito material.

\footnotetext{
${ }^{32}$ ABREU, Rafael Sirangelo de. "Customização processual compartilhada": o sistema de adaptabilidade do novo CPC. Revista de Processo, v. 257, p. 51-76, jul. 2016, p. 57.

33 Sobre o tema da previsibilidade: "[...] embora a previsibilidade processual requeira certo grau de formalidade, esse elemento não pode se converter em formalismo desfavorável à jurisdição. Fugindo desse risco, encontraria amparo a defesa por uma maior liberdade procedimental, e, no argumento "contratualista", a compreensão de que essa maleabilidade deveria passar pelo crivo (e pelo impulso) dos sujeitos em juízo. Em síntese, trata-se de defender que a neutralidade teoricamente trazida por um procedimento igualitário deveria ser superada em favor de uma maior adaptação ao caso concreto, e de arrematar destacando que caberia às partes papel de destaque nessa adequação". (ARENHART, Sérgio Cruz. OSNA, Gustavo. Os acordos processuais no novo CPC: aproximações preliminares. In. RIBEIRO, Darci Guimarães. JOBIM, Marco Félix. (Orgs.). Desvendando o Novo CPC. Porto Alegre: Livraria do Advogado, 2015.

${ }^{34}$ GAJARDONI, Fernando da Fonseca. Flexibilidade procedimental: um novo enfoque para o estudo do procedimento em matéria processual. Tese (Doutorado em Direito Processual) - Faculdade de Direito, Universidade de São Paulo, São Paulo, 2007.

${ }^{35}$ CABRAL, Trícia Navarro Xavier. Convenções em matéria processual. Revista de Processo, v. 241, p. 489516, mar. 2015, p. 491.

${ }^{36}$ DIDIER JR, Fredie. Ensaios sobre os negócios jurídicos processuais. Salvador: JusPodvm, 2018, p. 20.
} 
Enfim, é compreendendo esse enfoque que se pode retomar as indagações formuladas anteriormente, procurando enfrentar seus principais pilares. Em resumo, é viável que também na tutela coletiva a possibilidade de negociação sobre o processo assuma lugar? Em caso positivo, como assegurar a legitimidade do instituto - tendo em vista o cariz essencialmente representativo existente nessa área?

\section{Negócios Processuais na Tutela Coletiva: Da Admissão à Legitimidade}

As inquietações trazidas ao término do último tópico são, de fato, providas de rigorosa pertinência. E isso especialmente porque, se é pujante a percepção dos potenciais benefícios advindos dos negócios processuais, também ganha corpo o debate ligado aos seus possíveis limites. Isso, seja em sede comparada, seja na própria realidade brasileira - em percurso fomentado pela estrutura legislativa do mencionado art.190 do Código de Processo Civil.

Nesse debate, costuma entrar em cena o próprio valor público que as convenções podem ou não agregar, surgindo uma justificável preocupação com os seus impactos sobre a sociedade e sobre a nossa já exaurida máquina judiciária. A questão possui importância angular, não podendo ser deixada de lado ${ }^{37}$. Na doutrina brasileira, Antonio do Passo Cabral, em aprofundada investigação a respeito das convenções processuais, salienta a necessidade de olhares atentos (entre outros limites gerais e específicos) para a eventual colisão entre o seu conteúdo e o núcleo essencial das garantias do processo ${ }^{38}$. No âmbito comparado, a questão também é enfrentada por autores como Bone, indicando a impossibilidade de que as negociações maculem a legitimidade normativo-institucional do processo ${ }^{39}$, e por Resnik, suscitando o risco de que as convenções desvirtuem as funções contemporâneas da jurisdição

\footnotetext{
37 Assim, ARENHART, Sérgio Cruz. OSNA, Gustavo. Os "acordos processuais" no projeto de CPC aproximações preliminares. p.150-155.

38 "Identificada a garantia processual afetada, deve-se enxergar sua margem de disponibilidade. Para tanto, a tarefa é analisar se a convenção atinge seu âmbito de proteção intangível ou, na expressão consagrada no direito constitucional, seu núcleo essencial (...) nos acordos processuais, também se deve buscar a preservação de um núcleo elementar de garantias. Assim como a simples invocação de direitos fundamentais processuais não pode reduzir a autonomia privada a nada - porque a liberdade também é um direito constitucional - de outro lado o procedimento convencional deve respeitar a ideia de garantias mínimas do devido processo". CABRAL, Antonio do Passo. Ob. cit. p. 335-336.

${ }^{39}$ Ver, BONE, Robert G. Party Rulemaking: Making Procedural Rules Through Party Choice. In. Texas Law Review. v.90. Austin: University of Texas School of Law, 2012. p.1384 e ss.
} 
40.

As ressalvas, certamente, geram dúvida e insegurança. Por outro lado, mencionouse, ainda, que nossa própria opção legislativa contribui em alguma dimensão para esses aspectos. É que, embora o diploma processual estabeleça hipóteses em que seria possível o controle de validade dos negócios, a sua previsão é aparentemente lacônica. Disso, fomentase o debate a respeito de os limites ali postos serem, de fato, os únicos a serem considerados no balizamento do instituto.

Sob esse prisma, a dubiedade a respeito da suficiência dos parâmetros legais tende a inibir o próprio uso do instituto ${ }^{41}$. Em síntese, "é possível admitir negócios jurídicos processuais. Problema diverso consiste em saber se e quando eles existem, são válidos e eficazes". ${ }^{42}$

A presente constatação é também formulada por Antonio do Passo Cabral. Enfrentando o tema, o autor menciona que "o art. 190 encerra um regramento conciso, que não disciplina, nem mesmo em termos genéricos, inúmeros aspectos fundamentais dos acordos processuais. Qual o objeto possível do acordo processual? Quais critérios e parâmetros devem ser analisados pelo juiz ao avaliar a validade das convenções? Quem são os sujeitos que se vinculam pelas disposições da avença? São poucos os balizamentos contidos expressamente no CPC/2015" "43. Como consequência, percebe-se a existência de um decisivo espaço de penumbra ligado ao instituto.

Procurando minimizar o problema, uma primeira questão usualmente trazida é que referidos acordos, pela sua própria natureza e estrutura, deveriam observar os parâmetros

\footnotetext{
${ }^{40}$ Nesse sentido, RESNIK, Judith. Procedure as Contract. In. Notre Dame Law Review. v.80. Notre Dame: University of Notre Dame, 2005. p.593 e ss.

${ }^{41}$ Nesse sentido: "Para as atuais finalidades, porém, o principal ponto a ser extraído dessa série de aspectos é que o intenso debate a respeito dos contornos que os negócios processuais podem assumir ocasiona, sem sombra de dúvidas, insegurança nesse particular. Sendo assim, é evidente que a análise de custos e de benefícios ligada à customização do processo é impactada: não sendo certo se o Judiciário irá ou não chancelar o termo, a parte é logicamente desmotivada a firmá-lo - já que seus eventuais benefícios são colocados na berlinda". (OSNA, Gustavo. "Contratualizando o processo": três notas sobre os negócios jurídicos processuais (e seu possível "fracasso"). Revista Eletrônica de Direito Processual da UERJ, Rio de Janeiro, ano 14, v. 21, n. 2, p. 163-185, mai./ago. 2020, p. 176).

${ }^{42}$ YARSHELL, Flávio Luiz. Convenção das partes em matéria processual: rumo a uma nova era? In: CABRAL, Antonio do Passo; NOGUEIRA, Pedro Henrique (Coord.). Negócios Processuais. v. 1. 3. ed. Salvador: JusPodivm, 2017, p. 65.

${ }^{43}$ CABRAL, Antonio do Passo. Convenções processuais. 2. ed. Salvador: JusPodivm, 2018, p. 168.
} 
Rio de Janeiro. Ano 15. Volume 22. Número 3. Setembro a Dezembro de 2021

Periódico Quadrimestral da Pós-Graduação Stricto Sensu em Direito Processual da UERJ

Patrono: José Carlos Barbosa Moreira (in mem.). ISSN 1982-7636. pp. 410-433 www.redp.uerj.br

postos pela própria legislação material. ${ }^{44}$ Desse modo, para aferir a validade dos negócios jurídicos processuais, as regras preconizadas nos arts. 104,166 e 167, do Código Civil deveriam ser necessariamente observadas. Em linhas gerais, os referidos dispositivos determinam que, para que um negócio seja considerado válido, é necessária a presença de agente capaz e de objeto lícito, possível, determinado ou determinável, bem como que a forma seja prescrita ou não defesa em lei. ${ }^{45}$

De igual modo, um parâmetro por vezes posto nessa seara se relaciona com a observação da própria natureza cogente de determinada regra processual - tomando-se referido fator como limite para a admissibilidade do negócio ${ }^{46}$. Ainda assim, porém, o espaço para debate seguiria presente. Afinal, como já assentado por Barbosa Moreira, no que toca à correta identificação de normas cogentes e de normas dispositivas, é sensível a "dificuldade que às vezes se encontra em traçar linha divisória nítida entre as duas espécies de normas" ${ }^{47}$. Além disso, como enfatizam Marinoni, Arenhart e Mitidiero, eventual negociação que tocasse o próprio exercício de poderes jurisdicionais poderia se mostrar inadmissível, dada a imprescindibilidade de tais aspectos para a configuração de um processo justo $^{48}$.

Enfim, é nesse cenário repleto de interrogações que se pode aferir a viabilidade, ou

\footnotetext{
${ }^{44}$ Nesse sentido: "Portanto, aplica-se aos acordos processuais a sistemática da teoria geral dos negócios, regulada no direito civil, podendo o intérprete partir de algumas disposições do direito privado, adaptá-las e as aplicar aos acordos processuais no que tange aos requisitos, efeitos, limites a autonomia privada, sempre com o cuidado de tratar-se de uma espécie peculiar de negócio jurídico afeta ao ambiente publicista que é o processo". (CABRAL, Antonio do Passo. Convenções processuais. 2. ed. Salvador: JusPodivm, 2018, p. 285286).

${ }^{45}$ Em igual entender: "Como qualquer negócio jurídico, os negócios jurídicos processuais passam pelo plano da validade dos atos jurídicos. [...] Assim, para serem válidos, os negócios processuais devem: a) ser celebrados por pessoas capazes; b) possuir objeto lícito; c) observar forma prevista ou não proibida por lei (arts. 104, 166 e 167, Código Civil). (DIDIER JR, Fredie. Ensaios sobre os negócios jurídicos processuais. Salvador: JusPodvm, 2018, p. 33-34).

${ }^{46}$ BUENO, Cassio Scarpinella. Novo código de processo civil anotado. 3. ed. São Paulo: Saraiva, 2017, p. 233. Nesse sentido, pontua Leonardo Carneiro da Cunha que "os negócios jurídicos processuais devem situar-se no espaço de disponibilidade outorgado pelo legislador, não podendo autorregular situações alcançadas por normas cogentes. A legislação impõe, por exemplo, observância às normas de competência absoluta, permitindo, entretanto, negócios jurídicos típicos sobre competência relativa. Quer isso dizer que não é possível a celebração de negócio processual que modifique a competência absoluta". CUNHA, Leonardo Carneiro da. Negócios jurídicos processuais no processo civil brasileiro. In: CABRAL, Antonio do Passo; NOGUEIRA, Pedro Henrique (Coord.). Negócios Processuais. v. 1. 3. ed. Salvador: JusPodivm, 2017, p. 71.

${ }^{47}$ MOREIRA, José Carlos Barbosa. Convenções das partes sobre matéria processual. Revista de Processo, v. 33, p. 182-191, jan./mar. 1984, p. 184.

${ }^{48}$ MARINONI, Luiz Guilherme; ARENHART, Sérgio Cruz; MITIDIERO, Daniel. Novo curso de processo civil: tutela dos direitos mediante procedimento comum. v. 2. 2. ed. São Paulo: Revista dos Tribunais, 2016, p. 117.
} 
não, de que negócios processuais sejam celebrados também no campo do processo coletivo. E aqui, aproximando-nos do tema, quer parecer que a resposta é afirmativa. Em outras palavras, as mesmas razões que demonstram o cabimento de acordos coletivos ligados ao próprio direito material também devem chancelar que, no que toca o processo, seja admitida a celebração de convenções. Afinal, nada parece haver que justifique a elevação, entre os dois âmbitos, de algum fator de discrímen absoluto.

De fato, como brevemente mencionado, o ponto nodal para a compreensão do tema consiste no fato de os interesses inseridos na dimensão da tutela coletiva serem usualmente tidos como indisponíveis ${ }^{49}$ - o que, além de vedar sua transação na seara material, poderia fazê-lo também no campo processual. Contudo, já se indicou acima que essa premissa, caso tomada de modo peremptório, deve ser rejeitada ${ }^{50}$. Isso, até mesmo, porque negociar direitos, inclusive os indisponíveis, pode na prática se mostrar a melhor ou a única opção para sua efetiva proteção. ${ }^{51}$

Mais que isso, como notado por Cabral, "os interesses materiais em disputa podem ser indisponíveis, mas ainda assim as partes podem acordar sobre inúmeros aspectos processuais, como a eleição de foro, redistribuição de ônus da prova, suspensão do processo, dilação de prazos, preclusões e formalidades dos atos do processo". 52

E o inverso também é verdadeiro: se a indisponibilidade do direito material não impediria a negociação processual, o fato de o direito material discutido ser disponível não autorizaria, por si só, a disponibilidade sobre qualquer aspecto do processo. ${ }^{53}$ Afinal, como visto, os limites aplicáveis de modo específico aos acordos processuais são próprios e demandam especial controvérsia.

\footnotetext{
${ }^{49}$ SILVA, Jaqueline Mielke; XAVIER, José Tadeu Neves. Primeiras reflexões sobre o sistema de justiça multiportas e a tutela dos direitos coletivos. In: Sistema Multiportas e métodos integrados de resolução de conflitos. Elaine Harzheim Macedo; Marina Damasceno. (Org.). 1. ed. v. 1, p. 171-194, Porto Alegre: EdiPUCRS, 2018, p. 180.

${ }^{50}$ VENTURI, Elton. Transação de direitos indisponíveis? Revista de Processo, v. 251, p. 391-426, jan. 2016, p. 392-394. PINHO, Humberto Dalla Bernardina de. Acordos materiais e processuais nas ações civis públicas fundadas em atos de improbidade administrativa. In: Francisco Pereira Coutinho; Julia Gracia. (Org.). Atas do I curso sobre mecanismos de prevenção e combate à corrupção na Administração Pública. 1. ed. v. 1. Lisboa: CEDIS, 2019, p. 89.

${ }^{51}$ VENTURI, Elton. Transação de direitos indisponíveis? Revista de Processo, v. 251, p. 391-426, jan. 2016, p. 397-398.

${ }^{52}$ CABRAL, Antonio do Passo. Convenções processuais. 2. ed. Salvador: JusPodivm, 2018, p. 341.

${ }^{53}$ PINHO, Humberto Dalla Bernardina de. Acordos em litígios coletivos: limites e possibilidades do consenso em direitos transindividuais após o advento do CPC/2015 e da lei de mediação. Revista Eletrônica de Direito Processual da UERJ, Rio de Janeiro, ano 12, v. 19, n. 2, p. 118-148, mai./ago. 2018, p. 132.
} 
Sob esse prisma, assim, os acordos processuais também parecem compatíveis com a tutela coletiva. Dando um passo além, Thereza Alvim e Igor Martins da Cunha percebem o importante papel que o Termo de Ajustamento de Conduta pode desempenhar nessa jornada - sendo viável inserir em seu bojo cláusulas que digam respeito a ônus, poderes, faculdades e deveres processuais, para ajustar as questões procedimentais e processuais às especificidades do conflito. ${ }^{54}$

Essa conclusão, destaca-se, também pode ser retirada da previsão constante no art. 17, da Resolução n”, 118/2014 do CNMP, o qual dispõe que "as convenções processuais devem ser celebradas de maneira dialogal e colaborativa, com o objetivo de restaurar o convívio social e a efetiva pacificação dos relacionamentos por intermédio da harmonização entre os envolvidos, podendo ser documentadas como cláusulas de termo de ajustamento de conduta". Mais que isso, essa tendência foi encampada expressamente pelo Ministério Público - conforme é possível observar do teor do art. 16 da mesma Resolução, o qual dispõe que "segundo a lei processual, poderá o membro do Ministério Público, em qualquer fase da investigação ou durante o processo, celebrar acordos visando constituir, modificar ou extinguir situações jurídicas processuais”.

É sob esse viés, então, que a celebração de negócios jurídicos processuais na tutela coletiva parece possível. Isso, porém, não faz com que o tema não deva ser visto com um necessário tempero - compatível com as próprias peculiaridades dessa seara. Afinal, levando em conta a dinâmica representativa inerente a esse campo, como atribuir legitimidade a esses acordos? De que modo evitar que eles se mostrem lesivos aos sujeitos ausentes dos polos processuais, maculando sua proteção?

Investigando essas dubiedades, parece necessário frisar, primeiramente, que os próprios debates ligados aos limites objetivos dos negócios processuais (questão que, como visto, ainda é porosa) também seriam transpostos para a processualística coletiva. Adicionalmente, se mesmo no processo individual há questionamentos quanto à extensão das convenções, aqui é crível que o tema fosse visto com ressalvas ainda mais amplas ${ }^{55}$. Por consequência, haveria um frutífero caminho a ser explorado pela doutrina e pela

\footnotetext{
${ }^{54}$ ALVIM, Thereza; CUNHA, Igor Martins da. Termo de ajustamento de conduta, mediação e conciliação: uma breve reflexão a respeito do negócio jurídico que previne ou resolve conflito que envolve direitos difusos, coletivos e individuais homogêneos. Revista de Processo, v. 304, p. 379-404, jun. 2020, p. 384.

${ }^{55}$ MAGALHÃES JR, Alexandre Alberto de Azevedo. Convenção processual na tutela coletiva. 1. ed. Salvador: JusPodivm, 2020, p. 172-173.
} 
jurisprudência.

Por outro vértice, na perspectiva subjetiva do negócio a sua celebração na esfera coletiva também parece recomendar maior atenção. É que, como já destacado, é imanente à tutela coletiva que nem todos os sujeitos diretamente impactados pela decisão sejam ouvidos. Nesse ponto, residiria um dilema a ser constantemente considerado no âmbito dos acordos processuais. Em síntese, seria imprescindível considerar que a eventual convenção, de algum modo, tocaria o interesse de sujeitos que não a integram pessoalmente - razão pela qual poderia soar ilegítimo que minorasse de maneira indevida ou injustificada sua proteção.

Enfrentando esse ponto-cego com lentes mais amplas, porém, constata-se que esse quebra-cabeça em nada é exclusividade dos negócios processuais. Pelo contrário, sua constatação se insere no cerne da própria admissibilidade geral da autocomposição no processo coletivo. Além disso, também se faz presente nos debates ligados à condução do feito coletivo, e à sua higidez. Em todos os casos, são assim formados pontos de apoio a serem igualmente valorizados e considerados para a aceitação da convenção processual coletiva.

De fato, "é certo que pensar a autocomposição no âmbito do processo coletivo exige cautelas e pontos de atenção que não coincidem plenamente com aqueles do processo individual. As particularidades que marcam a proteção coletiva de direitos individuais, ou a proteção de direitos metaindividuais, exigem esse feixe de releituras e de recomposições" 56. Impõe-se, assim, redimensionar questões como a possibilidade de negociação que minore a publicidade de atos - vetor que, no âmbito da tutela coletiva, não parece viável ${ }^{57}$. Também, exige-se um exame criterioso da representatividade adequada - verificando se a convenção se dá, verdadeiramente, em observância aos interesses do grupo afetado e de modo a lhe gerar algum proveito ${ }^{58}$. O problema, em última análise, reverbera os desafios de legitimação que perpassam de um modo geral os fundamentos da tutela coletiva.

Como consequência, assume protagonismo o papel a ser desempenhado, na análise das convenções, pelo próprio órgão jurisdicional. Evidentemente aqui, para garantir a adequada representação, esse espectro de análise não poderá ser o mesmo usualmente pensado para o processo individual. Em síntese, se o papel do magistrado no processo

\footnotetext{
${ }^{56}$ ARENHART, Sérgio Cruz. OSNA, Gustavo. Curso de Processo Civil Coletivo.

${ }^{57}$ ARENHART, Sérgio Cruz. OSNA, Gustavo. Curso de Processo Civil Coletivo. p. 268 e ss.

${ }^{58}$ ARENHART, Sérgio Cruz. OSNA, Gustavo. Curso de Processo Civil Coletivo. p. 268 e ss.
} 
coletivo não pode ser o mesmo genericamente pensado para o processo individual, esse elemento também deve impactar a aferição dos negócios processuais - estabelecendo novos desafios.

Ilustrando essa reflexão, Alexandre Magalhães sustenta considerar inadmissível, por exemplo, uma convenção processual firmada em ação coletiva que viesse a excluir determinado grupo ou categoria do pedido sem justificativa adequada às circunstâncias fáticas ${ }^{59}$. Como se vê, o problema esbarra, então, na restrição de proteção assegurada pela tutela coletiva - vez que referido elemento iria na contramão dos próprios propósitos da matéria.

De qualquer modo, é certo que esse desafio segue presente e que, gradualmente, passará a ser acertado em nossos Tribunais. Se os negócios processuais são admissíveis na tutela coletiva e podem aí introduzir relevantes ganhos, é preciso observá-los com a cautela que o próprio processo coletivo justifica. Há, assim, um rico caminho a ser explorado pelo estudioso da matéria.

\section{Considerações Finais}

Conforme se pretendeu demonstrar no presente estudo, a tutela coletiva guarda peculiaridades que merecem especial atenção. Essas especificidades acabam por refletir na construção procedimental, impactando também a possibilidade de realização de acordos processuais - em face da inviabilidade de plena participação, na negociação, de todos os atores envolvidos. A referida problemática se intensifica, principalmente, em face da maior atenção que o tema da autocomposição tem recebido no processo civil brasileiro nos últimos anos, por meio de um estímulo à realização de acordos.

Como visto, embora a autocomposição no processo coletivo precise ser analisada com as cautelas que o tema exige, não há incompatibilidade imediata na realização de acordos nessa seara. Diante disso, no que diz respeito especificamente aos negócios jurídicos afetos ao processo, observou-se acima que essa adequação também se faz presente. Por certo, a análise é dificultada pelas próprias dubiedades que ainda caracterizam em nosso processo

\footnotetext{
59 MAGAlHÃeS JR, Alexandre Alberto de Azevedo. Convenção processual na tutela coletiva. 1. ed.
} Salvador: JusPodivm, 2020, p. 185-188. 
as convenções processuais e seus limites. Porém, a rejeição peremptória de sua celebração na seara coletiva não parece adequada.

É assim que se considera que esse acoplamento deve ser objeto de leituras e de construções. Afinal, embora admissível, a convencionalidade na tutela coletiva certamente deve levar em conta as particularidades dessa área. Questões como a máxima efetividade da proteção e o controle de representatividade assumem especial protagonismo - em um caminho rico e frutífero a ser compreendido e explorado.

\section{REFERÊNCIAS}

ABREU, Rafael Sirangelo de. "Customização processual compartilhada": o sistema de adaptabilidade do novo CPC. Revista de Processo, v. 257, p. 51-76, jul. 2016.

ALVIM, Thereza; CUNHA, Igor Martins da. Termo de ajustamento de conduta, mediação e conciliação: uma breve reflexão a respeito do negócio jurídico que previne ou resolve conflito que envolve direitos difusos, coletivos e individuais homogêneos. Revista de Processo, v. 304, p. 379-404, jun. 2020.

ANDREWS, Neil. O Moderno Processo Civil. Trad. Teresa Arruda Alvim Wambier. São Paulo: Ed. RT, 2009.

ARENHART, Sérgio Cruz. A tutela coletiva de interesses individuais: para além da proteção dos interesses individuais homogêneos. São Paulo: Ed. RT, 2013.

ARENHART, Sérgio Cruz. OSNA, Gustavo. Curso de Processo Civil Coletivo. 3 ed. rev., atual. e ampl. São Paulo: Ed. RT, 2021.

ARENHART, Sérgio Cruz. OSNA, Gustavo. Os acordos processuais no novo CPC: aproximações preliminares. In. RIBEIRO, Darci Guimarães. JOBIM, Marco Félix. (Orgs.). Desvendando o Novo CPC. Porto Alegre: Livraria do Advogado, 2015.

BONAVIDES, Paulo. Curso de Direito Constitucional. 25 ed. São Paulo: Malheiros, 2010.

BONE, Robert G. Party Rulemaking: Making Procedural Rules Through Party Choice. In. Texas Law Review. v. 90. Austin: University of Texas School of Law, 2012.

BUENO, Cassio Scarpinella. Novo código de processo civil anotado. 3. ed. São Paulo: Saraiva, 2017.

CABRAL, Antonio do Passo. Convenções Processuais. Salvador: JusPodivm, 2016. 
CABRAL, Antonio do Passo. Convenções processuais. 2. ed. Salvador: JusPodivm, 2018.

CABRAL, Antonio do Passo. O novo procedimento-modelo (Musterverfahren) alemão: uma alternativa às ações coletivas. In. Revista de Processo, v. 147. São Paulo: Ed. RT, 2007.

CABRAL, Trícia Navarro Xavier. Convenções em matéria processual. Revista de Processo, v. 241, p. 489-516, mar. 2015.

CADIET, Loïc. Los acuerdos procesales en derecho francés: situación actual de la contractualización del proceso y de la justicia en Francia. Civil Procedure Review, v. 3, n. 3, p. 3-35, ago./dez. 2012. Disponível em: <http://www.civilprocedurereview. com/teoria-geral-do-processo/456-los-acuerdos-procesales-en-derecho-francessituacion

-actual-de-la-contractualizacion-del-proceso-y-de-la-justicia-en-francia> Acesso em: 15 jun. 2020.

CRUZ E TUCCI, José Rogério. Class action e mandado de segurança coletivo, diversificações conceptuais. São Paulo: Ed. RT, 1990.

CUNHA, Alcides Munhoz da. Evolução das Ações Coletivas no Brasil. In. Revista de Processo. n.77. São Paulo: Editora Revista dos Tribunais, 1995.

CUNHA, Leonardo Carneiro da. Negócios jurídicos processuais no processo civil brasileiro. In: CABRAL, Antonio do Passo; NOGUEIRA, Pedro Henrique (Coord.). Negócios Processuais. v. 1. 3. ed. Salvador: JusPodivm, 2017.

DIDIER JR, Fredie. Ensaios sobre os negócios jurídicos processuais. Salvador: JusPodvm, 2018 .

DIDIER JR., Fredie. Negócios jurídicos processuais atípicos no Código de Processo Civil de 2015. In. Revista Brasileira da Advocacia, v.1. São Paulo: Ed. RT, 2016.

FISS, Owen. Against Settlement. In. Yale Law Journal. n.93. New Haven: Yale University Press, 1983.

GAJARDONI, Fernando da Fonseca. Flexibilidade procedimental: um novo enfoque para o estudo do procedimento em matéria processual. Tese (Doutorado em Direito Processual) - Faculdade de Direito, Universidade de São Paulo, São Paulo, 2007.

GIDI, Antonio. A Class Action como instrumento de tutela coletiva de direitos. São Paulo: Ed. RT, 2007. 
GIDI, Antonio. Class Actions in Brazil: A Model for Civil Law Countries. In. The American Journal of Comparative Law. n.51. Michigan: University of Michigan Law School, 2003.

GIDI, Antonio. Rumo a um Código de Processo Civil Coletivo. Rio de Janeiro: Forense, 2008 .

GRINOVER, Ada Pellegrini. Os processos coletivos nos países de civil Law e common Law: uma análise de direito comparado. São Paulo: Ed. RT, 2008.

GROSSI, Paolo. Primeiras Lições sobre o Direito. Trad. Ricardo Marcelo Fonseca. Rio de Janeiro: Forense, 2005.

HODGES, Christopher. The Reform of Class and Representative Actions in European Legal Systems. Oxford: Hart Publishing, 2008.

ISSACHAROFF, Samuel. Civil Procedure. New York: Foundation Press, 2005.

MAGALHÃES JR, Alexandre Alberto de Azevedo. Convenção processual na tutela coletiva. 1. ed. Salvador: JusPodivm, 2020.

MARINONI, Luiz Guilherme; ARENHART, Sérgio Cruz; MITIDIERO, Daniel. Novo curso de processo civil: teoria do processo civil. v. 1. 3. ed. São Paulo: Revista dos Tribunais, 2017.

MARINONI, Luiz Guilherme; ARENHART, Sérgio Cruz; MITIDIERO, Daniel. Novo curso de processo civil: tutela dos direitos mediante procedimento comum. v. 2. 2. ed. São Paulo: Revista dos Tribunais, 2016.

MEIRELLES, Hely Lopes. Mandado de segurança e ação popular. 10 ed. São Paulo: Revista dos Tribunais, 1985.

MENDES, Aluisio Gonçalves de Castro. Ações Coletivas no Direito Comparado e Nacional. 2 ed. São Paulo: Ed. RT, 2009.

MOREIRA, José Carlos Barbosa. Convenções das partes sobre matéria processual. Revista de Processo, v. 33, p. 182-191, jan./mar. 1984.

MULHERON, Rachael. The Class Action in Common Law Legal Systems: A Comparative Perspective. Oxford: Hart Publishing, 2004.

OSNA, Gustavo. Coletivização total e coletivização parcial: aportes comparados e o processo civil brasileiro. In. Revista de Processo Comparado. v. 1. São Paulo: Ed. RT, 2015. 
OSNA, Gustavo. "Contratualizando o processo": três notas sobre os negócios jurídicos processuais (e seu possível "fracasso"). Revista Eletrônica de Direito Processual da UERJ, Rio de Janeiro, ano 14, v. 21, n. 2, p. 163-185, mai./ago. 2020.

OSNA, Gustavo. Direitos Individuais Homogêneos: Pressupostos, Fundamentos e Aplicação no Processo Civil. São Paulo: Ed. RT, 2014.

PINHO, Humberto Dalla Bernardina de. Acordos em litígios coletivos: limites e possibilidades do consenso em direitos transindividuais após o advento do CPC/2015 e da lei de mediação. Revista Eletrônica de Direito Processual da UERJ, Rio de Janeiro, ano 12, v. 19, n. 2, p. 118-148, mai./ago. 2018.

PINHO, Humberto Dalla Bernardina de. Acordos materiais e processuais nas ações civis públicas fundadas em atos de improbidade administrativa. In: Francisco Pereira Coutinho; Julia Gracia. (Org.). Atas do I curso sobre mecanismos de prevenção e combate à corrupção na Administração Pública. 1. ed. v. 1. Lisboa: CEDIS, 2019.

PINHO, Humberto Dalla Bernardina de; VIDAL, Ludmila Camacho Duarte. Primeiras reflexões sobre os impactos do novo CPC e da Lei de Mediação no compromisso de ajustamento de conduta. Revista de Processo, v. 256, p. 371-409, jun. 2016.

RESNIK, Judith. Procedure as Contract. In. Notre Dame Law Review. v. 80. Notre Dame: University of Notre Dame, 2005.

ROQUE, André Vasconcelos. Class Action - Ações Coletivas nos Estados Unidos: o que podemos aprender com eles. Salvador: Editora JusPodivm, 2013.

SILVA, Jaqueline Mielke; XAVIER, José Tadeu Neves. Primeiras reflexões sobre o sistema de justiça multiportas e a tutela dos direitos coletivos. In: Sistema Multiportas e métodos integrados de resolução de conflitos. Elaine Harzheim Macedo; Marina Damasceno. (Org.). 1. ed. v. 1, p. 171-194, Porto Alegre: EdiPUCRS, 2018.

SILVA, José Afonso da. Curso de Direito Constitucional Positivo. 32 ed. São Paulo: Malheiros, 2009.

SILVA, Ovídio Araújo Baptista da; GOMES, Fábio Luiz; SILVA, Jaqueline Mielke; BAPTISTA, Luiz Fernando. Teoria geral do processo civil. 6. ed. São Paulo: Revista dos Tribunais, 2011.

TUCCI, Rogério Lauria. CRUZ E TUCCI, José Rogério. Constituição de 1988 e Processo. São Paulo: Saraiva, 1989. 
Revista Eletrônica de Direito Processual - REDP.

Rio de Janeiro. Ano 15. Volume 22. Número 3. Setembro a Dezembro de 2021

Periódico Quadrimestral da Pós-Graduação Stricto Sensu em Direito Processual da UERJ

Patrono: José Carlos Barbosa Moreira (in mem.). ISSN 1982-7636. pp. 410-433 www.redp.uerj.br

VENTURI, Elton. Transação de direitos indisponíveis? Revista de Processo, v. 251, p. 391426, jan. 2016.

YARSHELL, Flávio Luiz. Convenção das partes em matéria processual: rumo a uma nova era? In: CABRAL, Antonio do Passo; NOGUEIRA, Pedro Henrique (Coord.). Negócios Processuais. v. 1. 3. ed. Salvador: JusPodivm, 2017. 